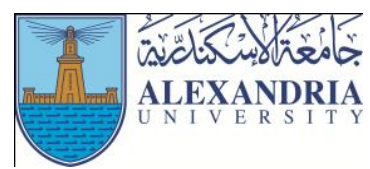

\title{
Health Awareness Level and Health Information Sources within Hail University Students in Light of Some Demographic Variables
}

\author{
Sameh Fawzi Abdel Fattah ${ }^{1}$ \\ ${ }^{1}$ Assistant Professor, Sport Health Sciences Department, Faculty of Physical Education, Al-Azhar University, Egypt
}

\begin{abstract}
:
This study aimed at: (1) Developing health awareness scale for preparatory year students at Hail University, (2) Identify health awareness level among preparatory year students at Hail University, (3) Identify relationship between health awareness level and health information sources between students according to some demographic variables (specialization, place of residence) and (4) Identify the most important health information sources between preparatory year students at Hail University. Three hundred students from preparatory year at Hail University participated in main study, their age ranged between 18-20 years. Questionnaire for measuring health awareness and identify health information resources between preparatory year students at Hail University used as data collection tool (prepared by researcher). The most important result were that: students, in general, have high level of health awareness, health program students are higher in health awareness level than students of engineering and human programs, and city students are higher in health awareness level than rural students.
\end{abstract}

\section{Introduction}

$\mathrm{H}$ ealth play a key role in various development areas for person, his family and society, Health awareness dissemination is of main priorities of health education in era of technological and industrial era where individual exposed to increased health and environmental risks.

The educational process, which does not end with behaviour and practice, have not achieved its full objectives. How people apply health information in their lives and the way they behave in event of a health problem and their health behaviour indicates their health awareness. (Hagar \& Amin, 2014, p3, 5)

Health awareness is citizens knowing health information.Health awareness should be the goal we seek. The goal should be changing people behaviour and habits and instil habits and traditions that will support health aspect and its development, such as "exercise and healthy nutrition". (Salama, 2007, p. 23)

Hence, the increasing attention to health awareness as a sound foundation for human health protection and development, which ultimately lead to the maintain health and the prevention of diseases (Al-Haron, 205)

Health awareness is important for growth and sound health, therefore, many studies interested in it as
Phongsavan (2005), Ulla Diez \& Perez-Fortis(2009), Abdulhak, Shanaas, Noairat, \& Al-Amd (2012), Al-Haron (2012), Khalfy (2013), Al-Anzi (2014), and Peltzer, Pengpid, Yung, Aounallah-Skhiri, \& Rehman (2015).

Al-Anzi (2014), quoted from Siham al-Hefnawi that health awareness is based on (3) aspects: Cognitive aspect, emotional aspect, and applied aspect. (Al-Anzi, 2014, p636-637)

Health awareness areas summarized from Abdulhak, Shanaa, Noairat, \& Al-Amd (2012), Al-Haron (2012), Khalfy (2013) Al-Anzi (2014) as follows:

1- Personal health: individual's general hygiene.

2- Nutrition: the process of eating, digestion, absorption and daily eating habits.

3- First aid: individuals' awareness in how to aid and deal with emergencies.

4- Environmental health: availability of health factors in environment

5- Mental and psychological health: individual extent of control his emotions and prevention of mental and psychological diseases. 
6- Diseases prevention: awareness of diseases and ways of its transmission, and preventing or limiting its spread.

7- Sports awareness: awareness of movement regular exercise importance,

The researcher chose university education stage because it is of great importance in formation of healthy habits, emphasis on it, and development of culture and awareness of healthy behaviour.

The researcher noted through his work at Hail University, and from his teaching of health and fitness course, a difference in health practices among the students in terms of personal and posture habits, health information, as well as the frequent inquiries of proper nutrition and sports programs suiting students.

Therefore, the researcher thought to conduct this study, this research is important because of that the issue of health awareness among university students is a vital topic, as the university sector plays a major role in spreading health awareness. This study opens the door for researchers to conduct studies on other Saudi universities in order to raise health level, universities are the last opportunity, through which the study can raise the level of personal, nutritional, environmental, sports and physical health education for students. Through this study, we can identify the most important sources from which students derive their health information to help them increase their health awareness.

\section{This study aims at:}

1- Developing health awareness scale for preparatory year students at Hail University

2- Identify health awareness level among preparatory year students at Hail University.

3- Identify relationship between health awareness level and health information sources between students according to some demographic variables (specialization, place of residence).

4- Identify the most important health information sources between preparatory year students at Hail University.

\section{The research hypotheses the following:}

1- There are statistically significant differences in health awareness level according to students' program (health / engineering / Humanity).
2- There are statistically significant differences in health awareness level according to students' program residence (rural / urban).

3- There is a difference in health information sources between preparatory year students

4- There are differences between the three programs (health, engineering, and Humanity) in health information sources.

\section{Research terms:}

\section{Health awareness:}

Individual's knowledge of health information and facts with his sense of responsibility towards his health and health of others. (Metwlly, Eid, Shoma, \& Ghamdy, 2004, p. 20)

Procedurally health awareness means the degree which student obtains on the health awareness scale used in the current study.

\section{Health information sources:}

Are the sources through which individuals obtain their health information whether written, audio, visual, electronic, or through family or university. (Procedural definition)

\section{Demographic variables:}

Fixed descriptive variables for each respondent such as gender, social status, educational level, economic and environmental level, and studied for their effect on a given variable and the extent of their relationship.

The researcher chose study program (health - engineering - Humanity) and residence (rural - urban) variables to study.

\section{Method}

\section{Subjects}

Two hundred students participated in pilot study. Three hundred students from preparatory year at Hail University participated in main study, their age ranged between 18-20 years with average of 19 years, divided as following: health program (100 students: 80 urban and 30 rural), Engineering program (100 students: 70 urban and 30 rural), and humanity program (100 students: 50 urban and 50 rural).

\section{Measures}

Questionnaire for measuring health awareness and identify health information resources between preparatory year students at Hail University (prepared by researcher) 


\section{Procedures}

\section{Questionnaire development}

\section{A- Questionnaire aspects identification}

Suggested aspects presented to experts (appendix 1) to express their opinion. Aspects got $80 \%$ approval accepted, which are six aspects: Personal health, food hygiene, sports health, posture health, preventive health, environmental health). Thirteen health information sources identified.

\section{B- Questionnaire phrases wording}

Suggested phrases presented to experts. Phrases got $80 \%$ approval accepted. Final questionnaire consisted of six aspects and Ninety phrases. Response on 3 level Likert scale (1 disagree, 2 sometimes, 3 very agreeable)

Questionnaire total score ranges from 90 to 270 marks. average mark (135), and (203) mark is efficiency limit which is $75 \%$ of total score scale.

\section{Questionnaire's psychometric characteristics:}

\section{I- Internal Validity}

Correlation calculated in between phrases, aspects and total score ranged between 0.268 and 0.927, all statistically significant at 0.01 , indicating the internal validity.

\section{II- Reliability:}

Alpha Cronbach reliability factors ranger between 0.748 and 0.940 , values which are high and approach complete 1.00. Correlation between administration, readministration on a sample of (30) students with time interval of two weeks ranged between 0.365 and 0.590 , values which are significant at 0.05 level, the matter which proof questionnaire reliability

\section{Main study implementation}

\section{1- Administrative procedures}

Hail university preparatory year deanship approval for applying this study obtained.

\section{2- Questionnaire administration}

Questionnaire administered on research sample in the period from $1 / 3 / 2016$ to $19 / 3 / 2016$.

\section{3- Questionnaire scoring}

Questionnaire scored as per determined scoring scale, questionnaires do not met set criteria excluded.

\section{- Statistical process:}

SPSS statistics software program (ver. 22) used to analyse research data.

\section{Results and Discussion}

\section{First hypothesis results and discussion}

"There are statistically significant differences in health awareness level according to students' program (health / engineering / Humanity).

To verify validity of this hypothesis, researcher calculated mean and standard deviations of students' score. In next Analysis of Variance used to verify significance of differences between means of the three groups (health, engineering, and Humanity). Table (1) shows Analysis of Variance results. 
Table (1)

Analysis of Variance for health awareness questionnaire between the three groups

\begin{tabular}{|c|c|c|c|c|c|c|}
\hline $\begin{array}{l}\text { Questionnaire } \\
\text { Aspects }\end{array}$ & Source & $\begin{array}{c}\begin{array}{c}\text { Sum } \\
\text { of } \\
\text { squares }\end{array} \\
\end{array}$ & $\begin{array}{c}\text { Degrees } \\
\text { of freedom }\end{array}$ & Mean square & $\mathbf{F}$ & Sig. \\
\hline \multirow{3}{*}{ Personal health } & Between groups & 3184.26 & 2 & 1592.12 & \multirow{3}{*}{62.525} & \multirow{3}{*}{0.001} \\
\hline & Within groups & 7613.72 & 299 & 25.464 & & \\
\hline & Total & 10798 & 301 & & & \\
\hline \multirow{3}{*}{ Food Hygiene } & Between groups & 1221.2 & 2 & 610.6 & \multirow{3}{*}{21.307} & \multirow{3}{*}{0.001} \\
\hline & Within groups & 8568.6 & 299 & 28.658 & & \\
\hline & Total & 9789.81 & 301 & & & \\
\hline \multirow{3}{*}{ Sport health } & Between groups & 1057.93 & 2 & 528.963 & \multirow{3}{*}{17.882} & \multirow{3}{*}{0.001} \\
\hline & Within groups & 8844.51 & 299 & 29.58 & & \\
\hline & Total & 9902.44 & 301 & & & \\
\hline \multirow{3}{*}{ Posture health } & Between groups & 597.936 & 2 & 298.968 & \multirow{3}{*}{8.416} & \multirow{3}{*}{0.001} \\
\hline & Within groups & 10622 & 299 & 35.525 & & \\
\hline & Total & 11219.9 & 301 & & & \\
\hline \multirow{3}{*}{ Preventive health } & Between groups & 363.168 & 2 & 181.584 & \multirow{3}{*}{6.597} & \multirow{3}{*}{0.001} \\
\hline & Within groups & 8230.53 & 299 & 27.527 & & \\
\hline & Total & 8593.7 & 301 & & & \\
\hline \multirow{3}{*}{$\begin{array}{c}\text { Environmental } \\
\text { Health }\end{array}$} & Between groups & 91.746 & 2 & 45.873 & \multirow{3}{*}{4.293} & \multirow{3}{*}{0.005} \\
\hline & Within groups & 3195.09 & 299 & 10.686 & & \\
\hline & Total & 3286.84 & 301 & & & \\
\hline \multirow{3}{*}{ Total } & Between groups & 29295.8 & 2 & 14647.9 & \multirow{3}{*}{22.403} & \multirow{3}{*}{0.001} \\
\hline & Within groups & 195495 & 299 & 653.828 & & \\
\hline & Total & 224790 & 301 & & & \\
\hline
\end{tabular}

The table above indicated that there are statistically significant differences health awareness questionnaire's aspects and the total score, where $\mathrm{F}$ values were at the significant at 0.01 level $(\mathrm{P}<0.01)$,
Table (2) shows mean and standard deviations of the three study groups in health awareness aspects.

Table (2)

Mean and standard deviation of the three study groups $(n=300)$

\begin{tabular}{|c|c|c|c|c|c|c|}
\hline \multirow{2}{*}{ Questionnaire Aspect } & \multicolumn{2}{|c|}{ Health program } & \multicolumn{2}{c|}{ Engineering program } & \multicolumn{2}{c|}{ Humanity program } \\
\cline { 2 - 7 } & Mean & SD & Mean & SD & Mean & SD \\
\hline Personal Health & 37.71 & 6.047 & 32.3 & 4.78 & 29.94 & 4.12 \\
\hline Food Hygiene & 33.9 & 6.28 & 32.75 & 4.98 & 29.17 & 4.66 \\
\hline Sport Health & 39.38 & 5.95 & 36.01 & 5.25 & 34.99 & 5.07 \\
\hline Posture Health & 37.32 & 7.03 & 35.65 & 5.44 & 33.87 & 5.26 \\
\hline Preventive Health & 34.38 & 6.59 & 32.13 & 4.46 & 31.97 & 4.39 \\
\hline Environmental Health & 22.76 & 4.17 & 21.57 & 2.6 & 21.6 & 2.81 \\
\hline Total & 205.45 & 29.16 & 190.44 & 24.67 & 181.55 & 22.44 \\
\hline
\end{tabular}

The table above indicates differences between the three groups, to determine differences direction and significance between groups, Scheffe test used (Table 3 ).

The level of health awareness for preparatory year students is high according, with a difference between the three programs in favour of health program. The mean of health program was $(76.09 \%)$ marks, engineering program was $(70.53 \%)$ and Humanity program was $(67.24 \%)$ of Health awareness questionnaire total score.

The researcher attributed this High level of health to increasing interest in health awareness in recent times, as the basis to build human being health by increasing his knowledge of health and development of his trends towards health. 
This is consistent with Al-Haron (2012), Khalfy (2013), and Al-Anzy (2014) study results that pointed out the need to provide health information based on scientific principles to develop students' attitudes towards healthy habits and practice in daily life.

The researcher also attributes this health awareness to multiplicity of sources from which students acquire their information and health trends throughout their life, especially with technological progress and easness of information accessibility.

Health culture acquired by students at the Hail University through successive and integrated curricula studied in previous education stages. This coincides with Khalfy
(2013), and Al-Anzy (2014) study results, which indicated that health awareness is the result of information acquired by the student through curricula during various years of education.

The weakness in health practices between students represented in smoking and obesity prevalence among students, attributed to weakness in application and practice of health information. This is consistent with Konczos et al. (2012) study results, which argued that persons' health behaviour considered the measurement or indicator for their health awareness, which proved poor health behaviour among female students despite their sport exercises and high level of health awareness.

Table (3)

Scheffe Post-Hoc comparison between groups in health awareness scale

\begin{tabular}{|c|c|c|c|c|}
\hline \multicolumn{2}{|c|}{$\begin{array}{l}\text { Questionnaire } \\
\text { Aspects }\end{array}$} & \multirow{2}{*}{$\begin{array}{c}\begin{array}{c}\text { Health } \\
\text { program }\end{array} \\
-\end{array}$} & \multirow{2}{*}{$\begin{array}{c}\begin{array}{c}\text { Engineering } \\
\text { Program }\end{array} \\
-\end{array}$} & \multirow{2}{*}{$\begin{array}{c}\text { Humanity } \\
\text { Program } \\
-\end{array}$} \\
\hline \multirow{3}{*}{ Personal health } & Health program & & & \\
\hline & Engineering Program & $5.40 *$ & - & - \\
\hline & Humanity Program & $7.76^{*}$ & $2.36^{*}$ & - \\
\hline \multirow{3}{*}{ Food Hygiene } & Health program & - & - & - \\
\hline & Engineering Program & 1.14 & - & - \\
\hline & Humanity Program & $4.72 *$ & $3.57^{*}$ & - \\
\hline \multirow{3}{*}{ Sport health } & Health program & - & - & - \\
\hline & Engineering Program & $3.36^{*}$ & - & - \\
\hline & Humanity Program & $4.38^{*}$ & 0.966 & - \\
\hline \multirow{3}{*}{ Posture health } & Health program & - & - & - \\
\hline & Engineering Program & 1.66 & - & - \\
\hline & Humanity Program & $3.44 *$ & 1.78 & - \\
\hline \multirow{3}{*}{ Preventive health } & Health program & - & - & - \\
\hline & Engineering Program & $2.24 *$ & - & - \\
\hline & Humanity Program & $2.40^{*}$ & 0.168 & - \\
\hline \multirow{3}{*}{$\begin{array}{c}\text { Environmental } \\
\text { Health }\end{array}$} & Health program & - & - & - \\
\hline & Engineering Program & $2.12^{*}$ & - & - \\
\hline & Humanity Program & $2.21 *$ & 0.098 & - \\
\hline \multirow{3}{*}{ Total } & Health program & - & - & - \\
\hline & Engineering Program & $15.00^{*}$ & - & - \\
\hline & Humanity Program & $23.89 *$ & $8.89 *$ & - \\
\hline
\end{tabular}

\section{* Difference is significant}

Table (3) results reveal significant differences between the three groups in health awareness level in all aspects where the best group were health program followed by engineering program and at end Humanity program. Differences wer significant between all the groups in all aspects except between Health and engineering programs in food hygiene and preventive health aspects, which were insignificant.
Table (3) also shows that level of health awareness of health and engineering programs is higher than level of health awareness of humanities program in all aspects. It also shows overall scores of the three groups, where students of the health program are the highest, engineering program come second, and at end humanities program

The researcher attributes this difference significance to high scientific and culture level of students in the health 
and engineering programs because of the nature of curricula in the scientific specialization in previous educational stages. As well as their study of some health syllabuses in university such public health and health and fitness syllabuses - authored by the researcher - which provides them with the necessary health information.

This is consistent with what Abdulhak et al (2012), Khalfy (2013), and Magdy and Mohamed (2013) who stressed that university is one of the most important institutions of society, which contribute in developing students' health awareness, especially health programs students, as teaching curricula with its contents and activities contribute in developing all aspects of health awareness.

Engineering program students studying Health and Fitness syllabus, which includes topics in sports, nutrition, posture, first aid and physical fitness, which undoubtedly contributed to their high level of health awareness.

Table (3) also indicates that highest aspect of health awareness questionnaire was (Sports Health) aspect for all programs, the mean for this aspect was (39.38) for health program, (36.02) for engineering program, (34.99) for humanities program, Personal health aspect came second for health program, and Physical health aspect came second for engineering and humanities program.

The researcher attributes this result to availability of sports centres and health clubs in Hail city, prompting youth to participate in these centres, thus increasing their sports awareness, as well as University provision of many stadiums and sports facilities on campus.

The Personal health aspect came in second place for health program, as students at this program are prepared to be future doctors, giving them the desire and the urgent need to take care of their personal health and to be good examples in their health field.
The Posture health aspect came in second place for engineering and humanities programs. The reason is the introduction of Department of Physical Education at Hail University, which represent a new job opportunity for students of these two programs. This has led students to take care of their sports and posture health to increase their chances of joining the department.

Table (3) also indicates that the lowest aspect in health awareness questionnaire between students is Environmental health.

The researcher believes that the reason for this is the lack of interest in this aspect in curricula and syllabuses, as well as the absence of personal responsibility for environment. This is consistent with Al-Haroun (2012) study, which attributed the low level of health awareness in some subjects to the lack of curricula dealing with it, like environment, first aid and other essential subjects.

The researcher also finds that aspect (environmental health) not addressed very much in previous studies, despite its close association with individual public health and its direct impact on personal and prevention health.

Second hypothesis results and discussion

"There are statistically significant differences in health awareness level according to students' program residence (rural / urban).

To verify validity of this hypothesis, researcher calculated mean and standard deviations of students' score. Independent $\mathrm{T}$ test used to verify significance of differences between means of the two groups (rural and urban). Table (4) shows T test analysis results.

Table (4)

Mean and standard deviations and $(T)$ value and its significance according to residence

\begin{tabular}{|c|c|c|c|c|c|c|}
\hline \multirow{2}{*}{ Variables } & \multicolumn{2}{|c|}{ Urban (n=50) } & \multicolumn{2}{c|}{ Rural (n=50) } & \multirow{2}{*}{ T } & \multirow{2}{*}{ sig } \\
\cline { 2 - 5 } & Mean & SD & Mean & SD & & $0.907^{* *}$ \\
\hline Personal Health & 37.58 & 4.911 & 30.64 & 5.13 & & 0.01 \\
\hline Food Hygiene & 34.96 & 4.21 & 30.08 & 5.51 & $4.975^{* *}$ & 0.01 \\
\hline Sport Health & 39.66 & 5.02 & 35.96 & 5.4 & $3.546^{* *}$ & 0.01 \\
\hline Posture Health & 39.74 & 4.29 & 34.1 & 5.72 & $5.570^{*}$ & 0.01 \\
\hline Preventive Health & 35.18 & 6.05 & 32.46 & 4.72 & $2.504^{*}$ & 0.05 \\
\hline Environmental Health & 24.2 & 3.45 & 21.96 & 2.66 & $3.628^{* *}$ & 0.01 \\
\hline Total & 211.32 & 21.94 & 185.2 & 25.47 & $5.493^{* *}$ & 0.01 \\
\hline
\end{tabular}

* Significant at $0.05(T$ significant $=2.627) * *$ Significant at $0.01(\mathbf{R}$ significant $=1.984)$ 
Table (4) results reveal significant differences between rural and urban in health awareness level towards urban student in all aspects.

This is due to health information sources multiplicity, as well as availability of health centres and sports clubs for city students, which accounted to more than thirty centres and clubs. It is worth mentioning that all health institutions provide activities throughout the year aimed at raising community's awareness of health issues. Researcher participated in many of these events.

Rural students lacking these activities, where student is keen to go to his place of residence after a long academic day, so he does not care much about activities held by health institutions in the city.
This is consistent with El-Asaf (2012) study, which pointed out absence of health awareness courses and seminars in rural areas, the matter that requires officials to pay attention to these villages and provide appropriate health awareness services to them as a right of all society members.

\section{Third hypothesis results and discussion}

"There is a difference in health information sources between preparatory year students"

The researcher calculated source using approval frequency and percentage as shown in table (5).

Table (5)

Frequency and percentages of using different information sources

\begin{tabular}{|c|c|c|c|}
\hline \multicolumn{2}{|l|}{ Source } & \multirow{2}{*}{$\begin{array}{c}\text { Frequency } \\
274 \\
\end{array}$} & \multirow{2}{*}{$\begin{array}{c}\% \\
91.70 \%\end{array}$} \\
\hline Medir & Yes & & \\
\hline Miedia & No & 26 & $8.70 \%$ \\
\hline \multirow{2}{*}{ Subjects you are studying in university } & Yes & 260 & $86.70 \%$ \\
\hline & No & 40 & $13.30 \%$ \\
\hline \multirow{2}{*}{ Subjects studies in previous education stages } & Yes & 218 & $72.70 \%$ \\
\hline & No & 82 & $27.30 \%$ \\
\hline \multirow{2}{*}{ Friends } & Yes & 258 & $86.00 \%$ \\
\hline & No & 42 & $14.00 \%$ \\
\hline \multirow{2}{*}{ Students activities (cultural, sport, and social) } & Yes & 254 & $84.70 \%$ \\
\hline & No & 46 & $15.30 \%$ \\
\hline \multirow{2}{*}{ Self reading } & Yes & 230 & $76.70 \%$ \\
\hline & No & 70 & $23.30 \%$ \\
\hline \multirow{2}{*}{ Training courses } & Yes & 222 & $74.00 \%$ \\
\hline & No & 78 & $26.00 \%$ \\
\hline \multirow{2}{*}{ Continues visits to health centers } & Yes & 210 & $70.00 \%$ \\
\hline & No & 90 & $30.00 \%$ \\
\hline \multirow{2}{*}{ Parents } & Yes & 236 & $78.70 \%$ \\
\hline & No & 64 & $21.30 \%$ \\
\hline \multirow{2}{*}{ Brochures } & Yes & 213 & $71.00 \%$ \\
\hline & No & 87 & $29.00 \%$ \\
\hline \multirow{2}{*}{ Seminars } & Yes & 212 & $70.70 \%$ \\
\hline & No & 88 & $29.30 \%$ \\
\hline \multirow{2}{*}{ Internet } & Yes & 293 & $97.70 \%$ \\
\hline & No & 7 & $2.30 \%$ \\
\hline
\end{tabular}

Table (5) show that health information sources using order was as follows: Internet (97.7)\%, Media (91.7\%), Subjects student are studying in university $(86.7 \%)$. Friends $(86 \%)$, Student activities $(84.7 \%)$, Parents $(78.7 \%)$, Self-reading (76.70\%), Training courses (74\%), Subjects studied in previous education stages $(72 \%)$, Brochures $(71 \%)$,
Seminars $(70.70 \%)$, Continues visits to health centres $(70 \%)$

The researcher in the opinion that Internet is in first rank among all sources is due to the availability of Internet un mobiles at any time and under any circumstances, students can access health information in an easy and interesting way. Many health web sites offer information in an 
attractive way that helps reader to move from one topic to another with all his attention.

This finding is consistent with Shive, Ma, Tan, \& Toubbeh (2007) study, where findings indicate differences between groups in sources of health information. Indian individuals relied on the World Wide Web for health information, while other sample groups' health information was World Wide Web, books, print materials, doctors, health professionals, family, groups of friends and health cultural seminars.

Media came in second rank is due to that media continue to play a role in educating society members, especially with the spread lack of movement diseases and the availability of satellite channels and radio programs specialized in health.

This result is consistent with Al-Jafry (2007) and AlDelimi, \& Al-Maaita (2014) study results, where they emphasized that media contribute significantly to building individual's convictions, attitudes and beliefs. Media, especially TV are of important means to develop society in all life areas, and in field of awareness in general, and health awareness in particular is an effective input to change of society behaviour towards healthy habits.)

Subjects student are studying in university came in third rank due to that this subjects have an effective role on their attitudes towards health, sports and nutrition, so that they find special interest among students.

The rest of health information sources effect is often limited, as students are not interested in interacting in seminars with a small number. Publications not read well but often not kept by the student, self-reading for students not interested for students unless for courses are tested. Health centres that provide treatment services to students do not give high priority to health awareness.

\section{Third hypothesis results and discussion}

"There are differences between the three programs (health, engineering, and Humanity) in health information sources"

The researcher calculated Chi square to identify difference between the three groups in using health information resources as shown in table (6).

Table (6)

Percentage and chi square value of differences between the three groups in using information sources.

\begin{tabular}{|c|c|c|c|c|c|c|}
\hline \multirow{2}{*}{ Source } & \multirow{2}{*}{\multicolumn{2}{|c|}{ Program }} & \multicolumn{2}{|c|}{ Reponses } & \multirow{2}{*}{ Chi Squar } & \multirow{2}{*}{ Significance } \\
\hline & & & Agree & Disagree & & \\
\hline \multirow{6}{*}{ Media } & \multirow{2}{*}{ Health } & Frequency & 94 & 6 & \multirow{6}{*}{3.622} & \multirow{6}{*}{0.164} \\
\hline & & $\%$ & $94.00 \%$ & $6 \%$ & & \\
\hline & \multirow{2}{*}{ Engineering } & Frequency & 93 & 7 & & \\
\hline & & $\%$ & $93 \%$ & $7 \%$ & & \\
\hline & \multirow{2}{*}{ Humanities } & Frequency & 87 & 13 & & \\
\hline & & $\%$ & $87 \%$ & $13 \%$ & & \\
\hline \multirow{6}{*}{ University } & \multirow{2}{*}{ Health } & Frequency & 93 & 7 & \multirow{6}{*}{6.288} & \multirow{6}{*}{0.05} \\
\hline & & $\%$ & $93.00 \%$ & $6 \%$ & & \\
\hline & Fnciperin & Frequency & 86 & 14 & & \\
\hline & Engineering & $\%$ & $86 \%$ & $14 \%$ & & \\
\hline & \multirow{2}{*}{ Humanities } & Frequency & 81 & 19 & & \\
\hline & & $\%$ & $81 \%$ & $19 \%$ & & \\
\hline \multirow{6}{*}{ Previous Information } & \multirow{2}{*}{ Health } & Frequency & 71 & 29 & \multirow{6}{*}{7.485} & \multirow{6}{*}{0.05} \\
\hline & & $\%$ & $71 \%$ & 13 & & \\
\hline & \multirow{2}{*}{ Engineering } & Frequency & 82 & 18 & & \\
\hline & & $\%$ & $82 \%$ & $18 \%$ & & \\
\hline & \multirow{2}{*}{ Humanities } & Frequency & 65 & 35 & & \\
\hline & & $\%$ & $65 \%$ & $35 \%$ & & \\
\hline \multirow{5}{*}{ Friends } & \multirow{2}{*}{ Health } & Frequency & 93 & 7 & \multirow{5}{*}{6.478} & \multirow{5}{*}{0.05} \\
\hline & & $\%$ & $93 \%$ & $7 \%$ & & \\
\hline & \multirow{2}{*}{ Engineering } & Frequency & 84 & 16 & & \\
\hline & & $\%$ & $84 \%$ & $16 \%$ & & \\
\hline & Humanities & Frequency & 81 & 19 & & \\
\hline
\end{tabular}


Sameh Abdel Fattah

\begin{tabular}{|c|c|c|c|c|c|c|}
\hline & & $\%$ & $81 \%$ & $19 \%$ & & \\
\hline \multirow{6}{*}{ Student activities } & \multirow{2}{*}{ Health } & Frequency & 91 & 9 & \multirow{6}{*}{7.754} & \multirow{6}{*}{0.05} \\
\hline & & $\%$ & $91.00 \%$ & $9 \%$ & & \\
\hline & \multirow{2}{*}{ Engineering } & Frequency & 86 & 14 & & \\
\hline & & $\%$ & $86 \%$ & $147 \%$ & & \\
\hline & \multirow{2}{*}{ Humanities } & Frequency & 77 & 23 & & \\
\hline & & $\%$ & $77 \%$ & $23 \%$ & & \\
\hline \multirow{6}{*}{ Self reading } & \multirow{2}{*}{ Health } & Frequency & 76 & 24 & \multirow{6}{*}{0.037} & \multirow{6}{*}{ Not significant } \\
\hline & & $\%$ & $76.00 \%$ & $24 \%$ & & \\
\hline & Engineering & Frequency & 77 & 23 & & \\
\hline & Engineering & $\%$ & $77 \%$ & $23 \%$ & & \\
\hline & \multirow{2}{*}{ Humanities } & Frequency & 77 & 23 & & \\
\hline & & $\%$ & $77 \%$ & $23 \%$ & & \\
\hline \multirow{6}{*}{ Training courses } & \multirow{2}{*}{ Health } & Frequency & 68 & 32 & \multirow{6}{*}{2.807} & \multirow{6}{*}{ Not significant } \\
\hline & & $\%$ & $68 \%$ & $32 \%$ & & \\
\hline & Fngineering & Frequency & 77 & 23 & & \\
\hline & Engineering & $\%$ & $77 \%$ & $23 \%$ & & \\
\hline & \multirow{2}{*}{ Humanities } & Frequency & 77 & 23 & & \\
\hline & & $\%$ & $77 \%$ & $23 \%$ & & \\
\hline \multirow{6}{*}{ Continues visits to health centres } & \multirow{2}{*}{ Health } & Frequency & 67 & 31 & \multirow{6}{*}{2.802} & \multirow{6}{*}{ Not significant } \\
\hline & & $\%$ & $67 \%$ & $31 \%$ & & \\
\hline & Fncincoring & Frequency & 78 & 22 & & \\
\hline & Linginecrimg & $\%$ & $78 \%$ & $22 \%$ & & \\
\hline & \multirow{2}{*}{ Humanities } & Frequency & 77 & 23 & & \\
\hline & & $\%$ & $77 \%$ & $23 \%$ & & \\
\hline & Health & Frequency & 82 & 8 & & \\
\hline & Heain & $\%$ & $82.00 \%$ & $8 \%$ & & \\
\hline Parents & Fngineering & Frequency & 77 & 23 & 0093 & Not sionificont \\
\hline & Engmeering & $\%$ & $77 \%$ & $23 \%$ & 0.993 & Not sigitilcant \\
\hline & Humonitios & Frequency & 77 & 23 & & \\
\hline & Humanities & $\%$ & $77 \%$ & $23 \%$ & & \\
\hline & Health & Frequency & 66 & 24 & & \\
\hline & Пеवіli & $\%$ & $76.00 \%$ & $24 \%$ & & \\
\hline Brochures & Engineering & Frequency & 70 & 30 & 3.011 & Not sionificant \\
\hline Brocnures & Engineering & $\%$ & $77 \%$ & $30 \%$ & 5.011 & \\
\hline & Humanities & Frequency & 77 & 23 & & \\
\hline & numamties & $\%$ & $77 \%$ & $23 \%$ & & \\
\hline & Health & Frequency & 62 & 38 & & \\
\hline & neditil & $\%$ & $62 \%$ & $38 \%$ & & \\
\hline Seminars & Engineering & Frequency & 73 & 27 & 5821 & Not sionificant \\
\hline seminars & Engineering & $\%$ & $73 \%$ & $27 \%$ & 5.821 & Not signiricant \\
\hline & Humanities & Frequency & 77 & 23 & & \\
\hline & Humanities & $\%$ & $77 \%$ & $23 \%$ & & \\
\hline & Heolth & Frequency & 96 & 4 & & \\
\hline & Healn & $\%$ & $67 \%$ & $4 \%$ & & \\
\hline Internet & Engineering & Frequency & 97 & 3 & 3803 & Not sionificant \\
\hline & Engineerming & $\%$ & $78 \%$ & $3 \%$ & 5.803 & Not signincant \\
\hline & Humanities & Frequency & 100 & 0 & & \\
\hline & Humanities & $\%$ & $77 \%$ & $0 \%$ & & \\
\hline
\end{tabular}


The previous table results reveal differences significance between the three groups in the following information sources only: subjects students are studying at the university, previous information, friends, and student activities) where students at health program were more dependent on these sources compared with engineering and humanities students. No significant differences between the three groups in other sources usage.

The researcher believes that is due to scientific study nature for health program students, whether in the scientific specialization in previous education stages or their courses that focus on everything related to public health, which makes them wish to obtain this information related to their future specialization. No doubt that University books well prepared and provides information to students in a specialized manner, especially with the adoption of training and not teaching method (training bags) as well as dealing with students through the Blackboard system, making subjects taught by university students ranked first among students of health program.

The third place among these sources as students exchange health information between themselves, because of their studies in health field.

Student activities came after, where students organize health awareness campaigns such as blood donation campaigns, anti-smoking and other student activities that contribute to building their health awareness.

This is consistent with Al-Anzy (2014) and AL-Salem (2015) studies, which confirmed that one of the main university roles is to address curricula that help students acquire health information through some elective courses such as health education, sports and health.)

\section{Conclusions}

1- Questionnaire used to measure the health awareness is effective

2- Students, in general, have high level of health awareness.

3- Health program students are higher in health awareness level than students of engineering and human programs.

4- City students are higher in health awareness level than rural students.

5- The most important sources of health information among Hail University students are Internet, media, and courses studied at university.
6- The lowest health information sources used among Hail University students are seminars, brochures, visits to health centres and self-reading.

7- Health program students rely more on subjects they study at university as information source.

8- The highest level of health awareness was in sports, posture and personal health aspects.

9- The lowest level of health awareness was in environmental health, food hygiene and prevention health aspects.

\section{Recommendations:}

1- It is necessary to pay attention to raise health awareness level among university students by adding special health courses, especially in humanities program.

2- There is need to pay attention to issues of environmental and preventive health awareness in health and study programs.

3- It is important to pay attention to health awareness programs in villages surrounding Hail city.

4- It is necessary that media pay attention to health awareness raising programs.

5- There is need to pay attention to student activities and set goals for it to raise students' health awareness level.

6- Conduct more studies on health awareness and its relationship to other variables, and different education stages.

7- Study the effect of syllabuses and their role in raising students' health awareness level.

8- Conduct more researches to measure health practices to identify students' health awareness level.

9- Conduct research on programs to raise health awareness among students using modern means of communication.

10- There is necessity of cooperation between universities departments and ministries of health and information to activate health programs and involve students in it.

11- Raising health awareness through university website and display screens available in all faculties.

12- Putting instructional boards inside classroom containing illustrations of correct posture conditions and some health guidelines. 


\section{References}

1- Abdulhak, E., Shanaaa, M., Noairat, Q. \& Al-Amd, S. (2012). Health awareness between Nagah National and Quds University. Nagah University Journal, 26(4), 939958. (In Arabic)

2- Al-Anzy, M. (2014). Health awareness between north borders university, Saudi Arabia. Journal of faculty of education, Al-Azhar University, 159(2) (In Arabic)

3- Al-Delimi, A., \& Al-Maaita, M. (2014). TV role in health awareness. First conference for health media, Oman, Jordan(In Arabic)

4- Al-Haron, M. (2012). Health awareness between students at faculties of education in Egypt and France. Arabic Education Future, 19(76), 205-286(In Arabic)

5- Al-Jafry, A. (2007). Health information sources, Health awareness level and its correlation with academic achievement for secondary school students in Riyadh, Saudi Arabia. Scitefic Hournal for physical education and sport, 52. (In Arabic)

6- AL-Salem, J. (2015). Public Health awareness level between students at faculty of physical education (Master thesis), Faculty of Physical Education, Yarmouk University, Saudi Arabia(In Arabic)

7- El-Asaf, F. (2012). Rural woman and its right in sufficient food. Egypt: National centre for human rights. (In Arabic)

8- Hagar, S. \& Amim, M. (2014). Helath and fitness. Riyadh, Saudi Arabia: Qelaa Alelm (Castles of science) for publishing. (In Arabic)

9- Khalfy, A. (2013). Effect of health locus of control on health awareness among university students in Algeria. Social and human sciences, 13, 269-284(In Arabic)

10- Konczos, C., Bognár, J., Szakály, Z., Barthalos, I., Simon, I., \& Oláh, Z. (2012). Health awareness, motor performance and physical activity of female university students. Biomedical Human Kinetics, 4, 12-17. DOI: 10.2478/v10101-012-0003-3

11- Magdy, M., \& Mohamed, N. (2013). Evaluation of health culture level between Assiut University students. Sport sciences in Arabic spring heart, Assiut University, Egypt. (In Arabic)

12- Metwlly. A., Eid, M., Shoma, I., \& Ghamdy, A. (2004). Health culture basis and concepts. Jeddah, Saudi Arabia. Andalus for publishing and distribution. (In Arabic)

13- Peltzer, K., Pengpid, S., Yung, T. K., AounallahSkhiri, H., \& Rehman, R. (2015). Comparison of health risk behavior, awareness, and health benefit beliefs of health science and non-health science students: An international study. Nursing \& Health Sciences, 18(2), 180-187. doi:10.1111/nhs. 12242

14- Phongsavan, P. (2005). Health behaviour and lifestyle of Pacific youth surveys: a resource for capacity building. Health Promotion International, 20(3), 238-248. doi:10.1093/heapro/dah612

15- Salama, B. (2007). Health and health education. Cairo, Egypt: Dar Elfekr AlAarby (Arab Thought house) (In Arabic)

16- Shive, S., Ma, G., Tan, Y., \& Toubbeh, J. (2007). Asian American subgroup differences in sources of health information and predictors of screening behavior. Californian Journal of Health Promotion, 5(2), 112-127.

17- Ulla Diez, S. M., \& Perez-Fortis, A. (2009). Sociodemographic predictors of health behaviors in Mexican college students. Health Promotion International, 25(1), 85-93. doi:10.1093/heapro/dap047 